\title{
Social Appropriation of Knowledge as a Key Factor for Local Development and Open Innovation: A Systematic Review
}

\author{
José-María Romero-Rodríguez ${ }^{1, * \mathbb{D}}$, María-Soledad Ramírez-Montoya ${ }^{2}$, \\ Inmaculada Aznar-Díaz ${ }^{1}$ (D) and Francisco-Javier Hinojo-Lucena ${ }^{1}$ (D) \\ 1 Department of Didactics and School Organization, University of Granada, 18071 Granada, Spain; \\ iaznar@ugr.es (I.A.-D.); fhinojo@ugr.es (F.-J.H.-L.) \\ 2 School of Humanities and Education, Tecnológico de Monterrey, Monterrey 64849, Mexico; \\ solramirez@tec.mx \\ * Correspondence: romejo@ugr.es
}

Received: 1 June 2020; Accepted: 17 June 2020; Published: 19 June 2020 updates

\begin{abstract}
The social appropriation of knowledge is an emerging descriptor in political agendas, since it drives social development and innovation. The relevance of this strategy lies mainly in the fact that scientific knowledge is made available to the population for its use and application. The purposes of this study were to identify the context and purpose presented by the experiences of social appropriation of knowledge, and to analyze the linkage of the experiences with the sectors that make up the pentahelix. To this end, a systematic review methodology was proposed in the Web of Science (WOS) and SCOPUS. Following the application of the inclusion and exclusion criteria, a total of 14 articles were analyzed. The results showed the emergence of this term, the geographical location of all experiences in Latin America, and the diversity of application of knowledge to favor local development. At the same time, it is shown that the institutions belonging to the government have developed experiences of social appropriation of knowledge in all other sectors of the pentahelix. Finally, we discuss the findings and implications of this study that showed the diverse experiences of social appropriation of knowledge and investigated this concept in connection to open science.
\end{abstract}

Keywords: social appropriation of knowledge; social innovation; citizen participation; open science; systematic review

\section{Introduction}

The development of technology and open access to the Internet has favored the accumulation of knowledge with the potential to transform the social environment [1-3]. Open science is also booming because of the wide availability of data and information online [4]. This has resulted in a large body of open access knowledge being available today. However, the vast amount of data sometimes dilutes the true and effective information among the merely false and worthless [5,6]. Expert support is therefore essential if some form of scientific knowledge is to be applied to a given context, in order to reduce uncertainty. Furthermore, success stories of open innovation are now being documented, which can be extrapolated to other contexts [7].

Thus, the most widely used concept of open innovation is that of Henry Chesbrough [8], which refers to the reciprocity of valuable ideas that can come from inside or outside institutions and can reach to the market [9]. In this context, the concept of social appropriation of knowledge (SAK) has gained strength in recent times, which is defined as the process through which a society makes scientific and technological knowledge available to all its members so that they can adapt and 
apply it to their own needs [10]. That is, scientific knowledge is available to the public, implying that anyone has access to knowledge and can apply it; hence, the importance of promoting initiatives that empower citizens and enable local development. SAK is closely linked to the processes of open innovation, since valuable ideas arise within the institutions and these are collected by the citizens to make use of the knowledge and contribute to the improvement of that knowledge, in turn generating new valuable ideas.

On the other hand, SAK is a mechanism of social entropy as it is a cyclical, complex, and dynamic phenomenon [11]. This process presents the key aspects of entropy, as the SAK attempts to limit uncertainty through the information needed to solve specific problems. Specifically, social entropy is "the state of order and social structuration of any given social interaction space" [12]. Furthermore, social entropy is related to the increase of Shannon information of the probability distribution of readers' attribution of veracity scores on a scientific information, brought about by open scrutiny and debate [13]. However, for this work, the concept of social entropy is mainly related to the part linked to the social structuring of the spaces of interaction. Therefore, the SAK propitiates a space of interaction from the appropriation of the scientific knowledge, which entails a process of social structuring when applying this knowledge to favor the development of the community.

In particular, there is interest in the SAK in the Latin American environment, an example of which is the Colombian government's national strategy for the appropriation of science, technology, and innovation, which is being applied around four lines of action-citizen participation, communication, transfer and exchange of knowledge, and knowledge management for the appropriation of knowledge [14]. On the other hand, there is also some concern in Brazil, where the lines of action are highlighted regarding the promotion of institutionalization and increase of resources, the creation of a National Agency for Public Communication, the establishment of legislation that promotes and encourages the communication of science and allows for greater autonomy in the management of teaching and research institutions [15]. In Ecuador, the main lines of action revolve around developing policy guidelines to generate a methodological framework for implementation, with attention to recommendations from international experts, and to learn about the guidelines for the social appropriation of technology in education [16]. This interest probably lies in the fact that the SAK generates continuous processes of social learning and encourages the economic development and competitiveness of countries [17]. Likewise, promoting the SAK entails the social improvement of the environment, while taking advantage of the results of scientific research, due to the use of the knowledge generated mainly in the universities to apply it to local problems [18,19].

In this sense, some of the main initiatives of SAK are linked to the creation of archives or repositories to preserve cultural documents [20]. However, the development of workshops, activities, conferences, or talks that bring knowledge closer to the population are other lines of action.

On the other hand, it is important to know how to characterize an SAK experience, which is related to the application of the SAK in a given context. Daza-Caceido et al. [21] established 10 indicators for their identification, among which are:

(1) Interest in science and technology

(2) Learning in science and technology

(3) Participation in the public sphere

(4) Inclusion of groups in vulnerable situations

(5) Strengthening of school educational practices

(6) Exchange and co-production of knowledge

(7) Incentive to scientific vocations

(8) Informed decision making

(9) Generation of innovations from science and technology

(10) Capacity-building for social appropriation of science and technology 
These indicators are situated in the same line of argument as Colciencias, where the SAK is a key factor in encouraging scientific knowledge, citizen participation, and social innovation [22]. In particular, social innovation has been promoted by political agendas as a strategy for local development [23], since social innovation refers to the resolution of social and environmental problems taking into consideration technology, citizen awareness, and creativity [24].

Recently, the development of social innovation initiatives has been encouraged to promote regional development, by linking universities, business, and the government [25]. In addition to this idea, the concept of the pentahelix was established by the National Council of Science and Technology of Mexico (CONACyT), which links the strategic sectors for sustainable development and open innovation, the government, society, academia, business, and the environment [26]. Thus, unlike the Quadruple-Helix model [27], it includes a new stratum - the environment-which is an essential factor for the SAK and its relationship with the international agenda of the United Nations' Sustainable Development Goals (SDG) [28]

In short, the interest of this study lies in the emerging nature of the social appropriation of knowledge. From this concept will be derived the lines of action of the future and, therefore, it is essential to establish the theoretical bases and review the body of knowledge generated in the last 10 years, on this term. Therefore, the objectives of the review were-(i) to identify the context and purpose presented by the experiences of social appropriation of knowledge and (ii) to analyze the linkage of the experiences on social appropriation of knowledge with the sectors that make up the pentahelix.

Furthermore, five research questions guided the structure of the paper and focused the search for information. These questions were asked, following the indications of previous systematic review studies [29,30], and according to the objectives of the study. In this sense, it was of interest to collect these data to extensively address the experiences of SAK published in an article format.

RQ1. How many studies are in the WOS and SCOPUS databases on social appropriation of knowledge from January 2009 to 2019 ?

RQ2. What is the geographical distribution of experiences of social appropriation of knowledge?

RQ3. In which sector of the pentahelix (government, society, academia, business, and environment) did experiences of social appropriation of knowledge develop?

RQ4. Which are the institutions that developed the experiences of social appropriation of knowledge?

RQ5. What was the purpose of the experiences of social appropriation of knowledge?

\section{Method}

A systematic review of the literature was proposed as a methodological approach [31], to answer the research objectives and questions posed. The review process was based on the protocol set out in the PRISMA declaration (Preferred Reporting Items for Systematic reviews and Meta-Analyses) [32]. This protocol was applied as a quality criterion that provides rigor to the systematic review research studies. Thus, based on the PRISMA report and previous works [33-37], the process followed for the identification of the scientific articles was constituted (Figure 1). This process involved two distinct stages (planning and action), with the aim of establishing a standardized protocol that could be replicated by different researchers. 


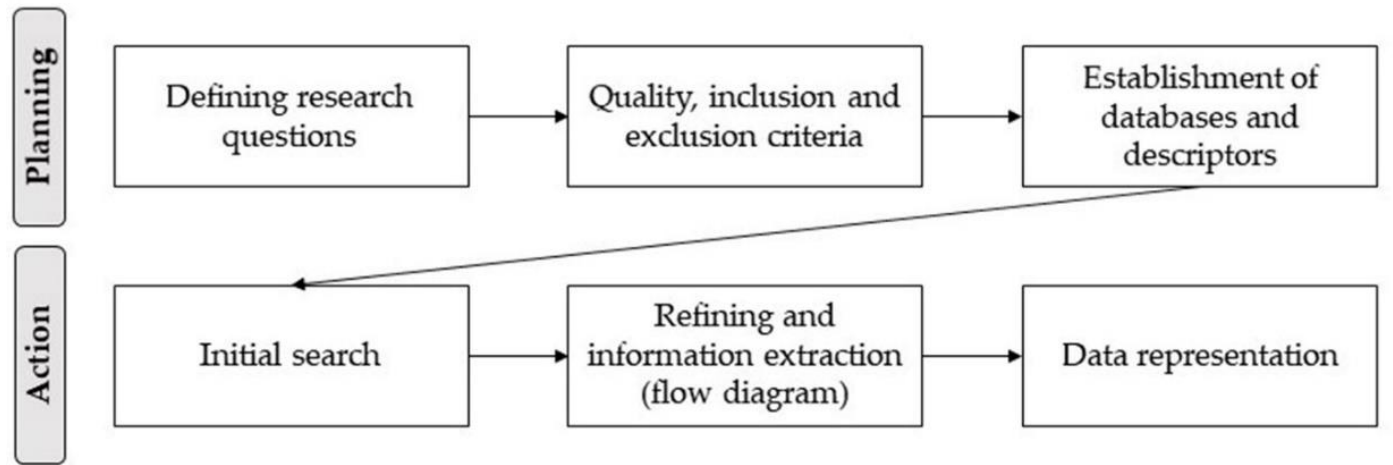

Figure 1. The systematic literature review process.

\subsection{Search Strategy}

The databases selected were Web of Science (WOS) and SCOPUS, due to their international recognition and quality standards. Depending on the topic of the study, the search descriptors in both databases were established (Table 1).

Table 1. Search descriptors.

\begin{tabular}{cc}
\hline WOS & SCOPUS \\
\hline TS $=$ ("social appropriation” AND knowledge) \\
Document type = article \\
Time period = 2009-2019 & TITLE-ABS-KEY ("social appropriation” \\
Andex = SCI-EXPANDED, SSCI, A\&HCI, CPCI-S, CPCI-SSH, & DNowledge) \\
BKCI-S, BKCI-SSH, ESCI, CCR-EXPANDED, IC & Dime period = 2009-2019 \\
\hline
\end{tabular}

These descriptors were applied in the WOS and SCOPUS search engine. In the selection of studies, different inclusion and exclusion criteria were introduced, in order to proceed with the refinement of the scientific literature (Table 2), according to the objectives and research questions of the study. In turn, four quality assurance criteria were developed, which are presented below:

QA1. Was the research title and abstract of this paper interrelated with the social appropriation of knowledge?

QA2. Is there sufficient description of the research methodology in the included study?

QA3. Was the explanation of the context in which the research was conducted adequate?

QA4. Have the objectives of the study been clear?

Table 2. Inclusion and exclusion criteria.

\begin{tabular}{ll}
\hline Inclusion Criteria (IC) & Exclusion Criteria (EC) \\
\hline & EC1: Proceedings, book chapters, books or other \\
IC1: Articles. & types of non-peer reviewed publications. \\
IC2: Articles published between the years 2009-2019. & EC2: Articles before 2009.EC3: Theoretical or review \\
IN3: Empirical work on experiences of social & papers. \\
appropriation of knowledge. & EC4: Works that did not collect experiences of social \\
& appropriation of knowledge. \\
\hline
\end{tabular}

The study selection was performed by two investigators using the same search protocol, in order to avoid study selection bias [38]. The degree of agreement of the two researchers was $100 \%$, so there were no discrepancies in the final selection of studies. 


\subsection{Data Collection and Analysis}

The PRISMA protocol divided the screening process into four phases [32], represented graphically in the flow diagram (Figure 2). In the identification phase, the total amount of items was collected after entering the search equation. Subsequently, the screening phase made it possible to reduce the number of articles by eliminating duplicate citations and applying the inclusion and exclusion criteria. In the eligibility phase, the title and summary of each scientific article were analyzed, and an attempt was made to ensure that each article responded to the quality questions posed and to the inclusion (IC3) and exclusion (EC3 and EC4) criteria. Finally, in the inclusion phase, the full text of each study was reviewed in detail, taking into consideration the previously established protocol.

The search was conducted on 10 January 2020 and included all articles published in the range of January 2009 to 2019.

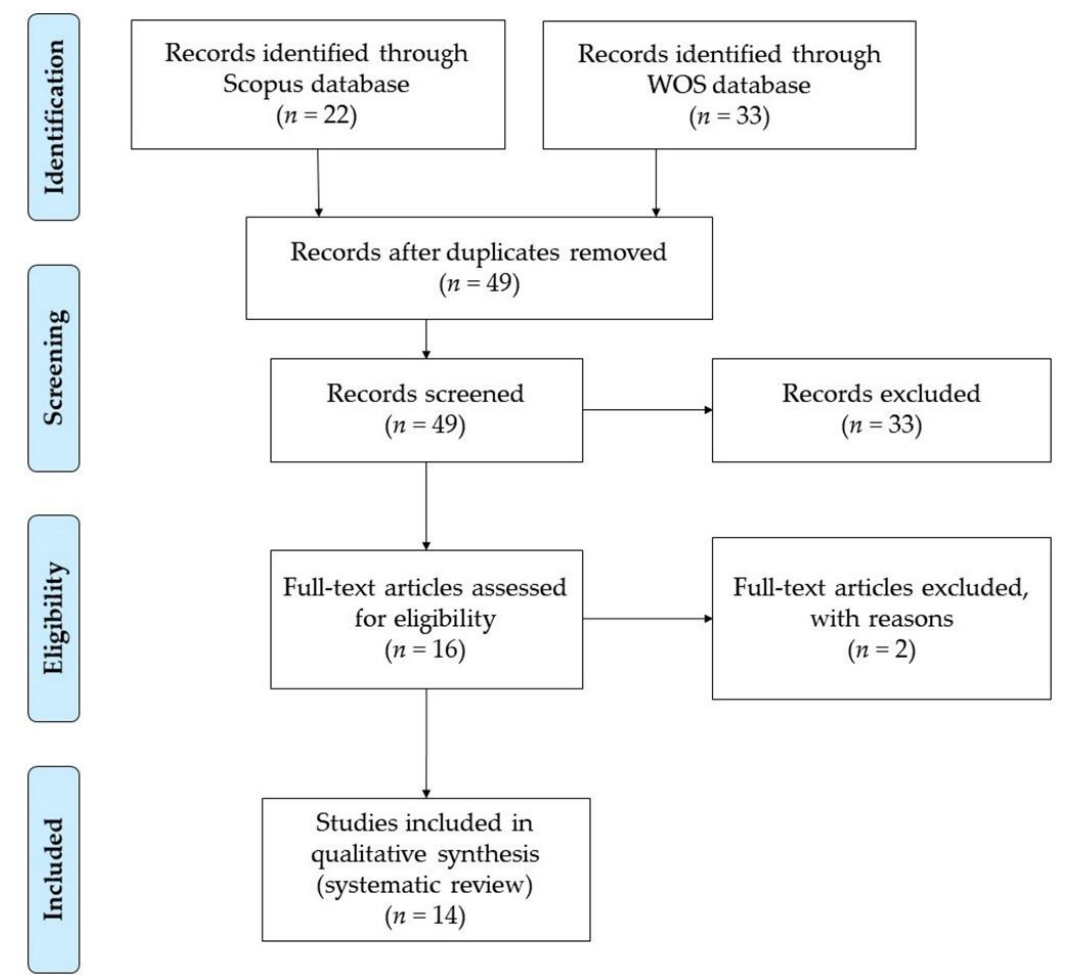

Figure 2. Flow diagram.

Data were collected and analyzed using the Excel software (Microsoft, Washington, USA), Professional Plus 2013 version. In addition, graphs were developed with the help of the Tableau software (Washington, USA) version 2019.3., and the Pajek software (Ljubljana, Slovenia) version 5.8.

\section{Results}

The presentation of results was grouped according to the different RQs proposed. In each one, data corresponding to the answer sought were grouped together.

3.1. RQ1. How Many Studies Are in the WOS and SCOPUS Databases on Social Appropriation of Knowledge from January 2009 to 2019

A total of 14 studies were published in the last 10 years. Although the first experience was from 2009 , most of them were developed in the last five years $(64.28 \%)$, which denote a certain emergence of the topic. Specifically, WOS included eight studies (57.14\%) and Scopus included six (42.86\%) (Figure 3). 


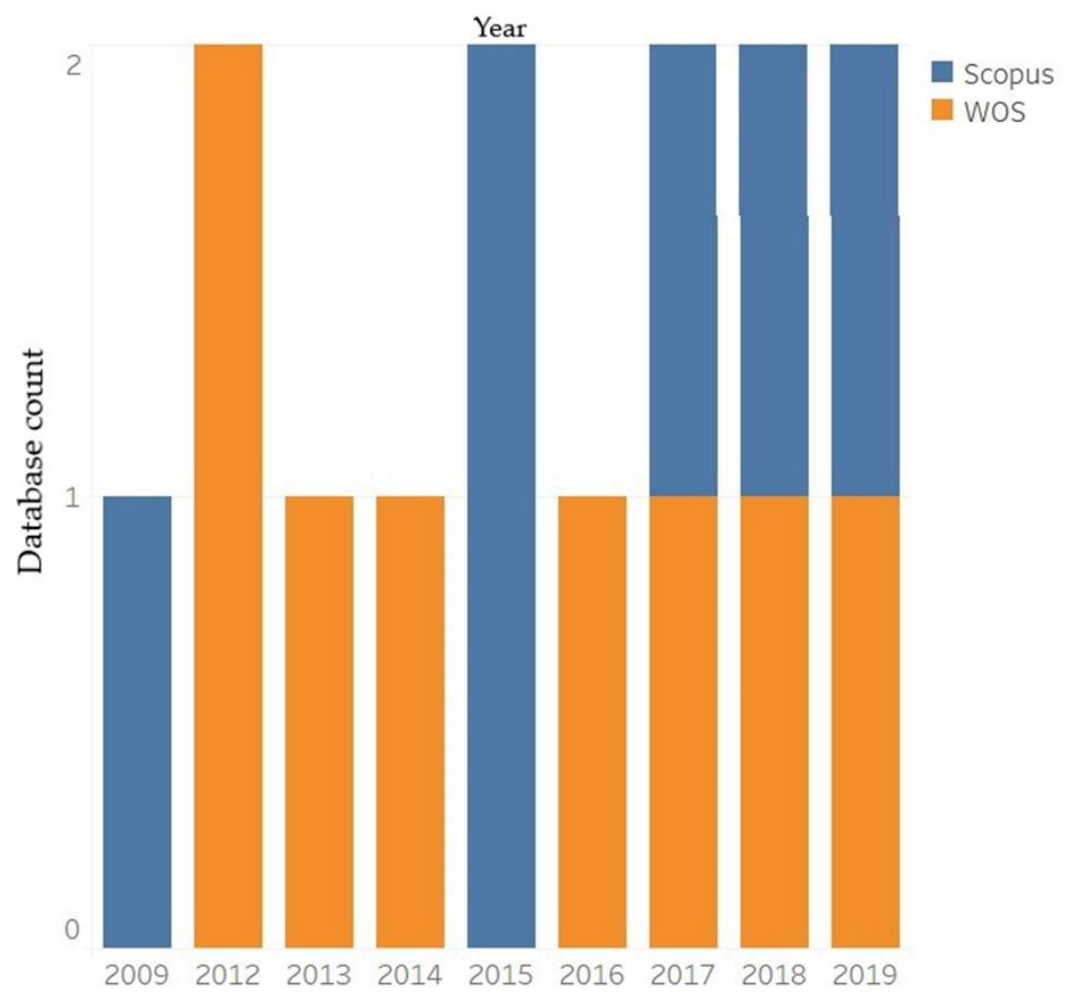

Figure 3. Grouping of articles by year and database.

3.2. RQ2. What Is the Geographical Distribution of Experiences of Social Appropriation of Knowledge

Of the 14 SAK experiences, nine were developed in Colombia (64.28\%), three in Mexico (21.44\%), one in Venezuela $(7.14 \%)$, and one in Uruguay $(7.14 \%)$. The geographical distribution of the SAK was specifically in Latin America, where 100\% of the experiences were applied (Figure 4).

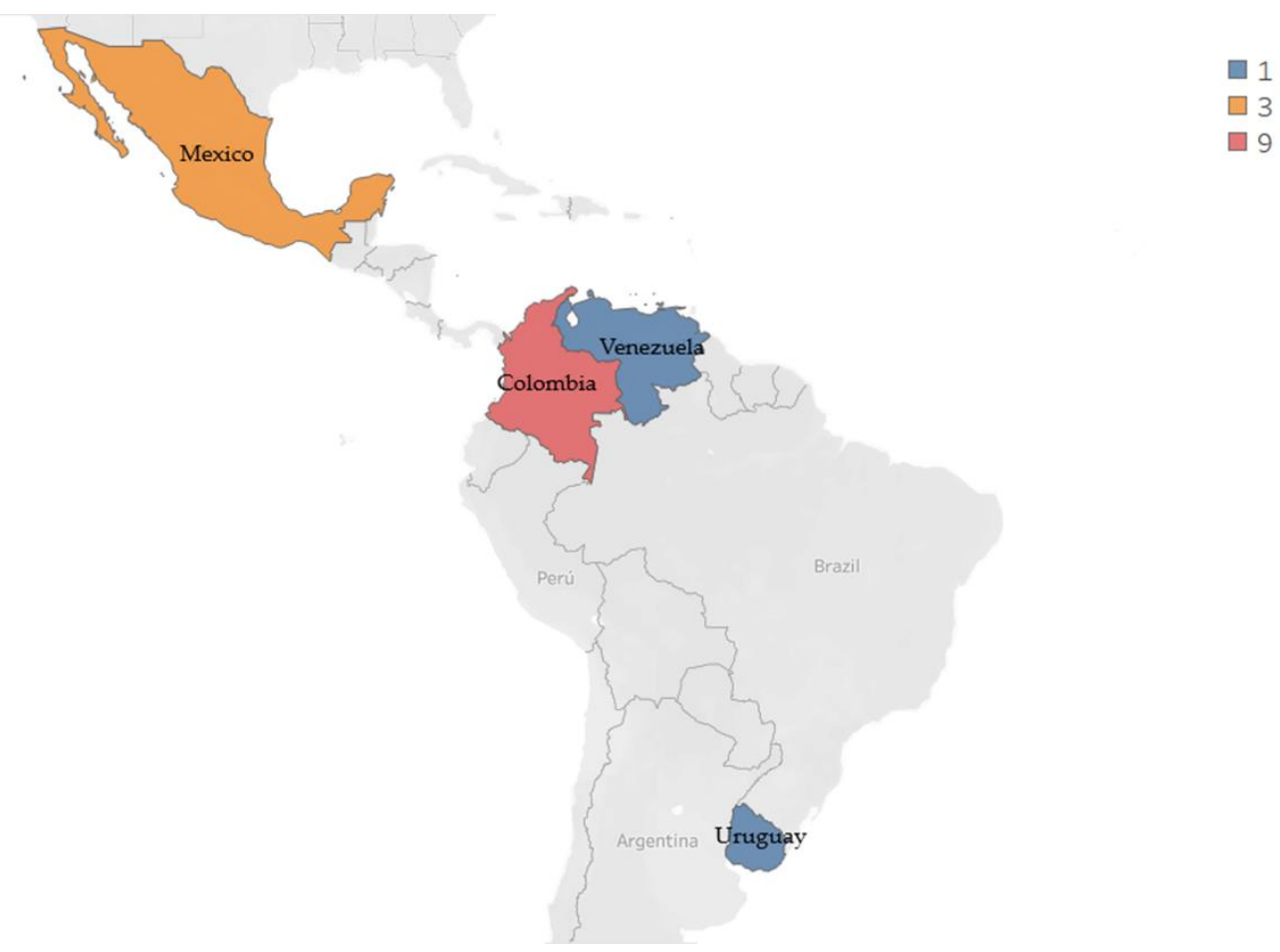

Figure 4. Geographical distribution of the experiences of social appropriation of knowledge (SAK). 
3.3. RQ3. In Which Sector of the Pentahelix (Government, Society, Academia, Business, and Environment) Did Experiences of Social Appropriation of Knowledge Develop?

SAK's experiences were grouped around four sectors of the pentahelix (Figure 5). Government was the only sector where none of the SAK experiences developed so far were focused. In contrast, the sector that had concentrated most of the experiences was society, with five experiences in total $(35.71 \%)$. The environmental sector was also of interest, gathering four experiences $(28.57 \%)$, and finally, the academy had three $(21.44 \%)$ and business had two experiences $(14.28 \%)$.

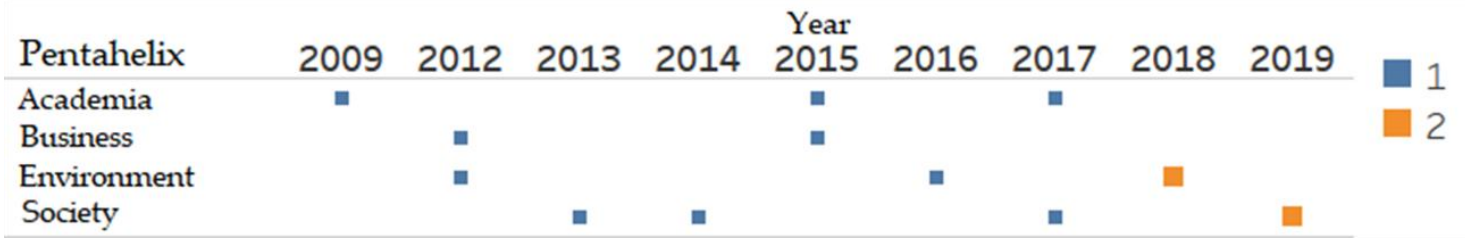

Figure 5. Grouping of SAK's experiences by pentahelix sector and year.

\subsection{RQ4. Which Are the Institutions That Developed the Experiences of Social Appropriation of Knowledge}

Despite the fact that the majority of experiences were focused on the social sector, the majority of the weight in the development of SAK experiences was carried out by the academic sector. Similarly, other relationships were established between institutions belonging to a different sector than that of application (Figure 6). This was the case for the government sector institutions that focused on the remaining four sectors. In turn, all sectors developed SAK expertise in the environmental sector.

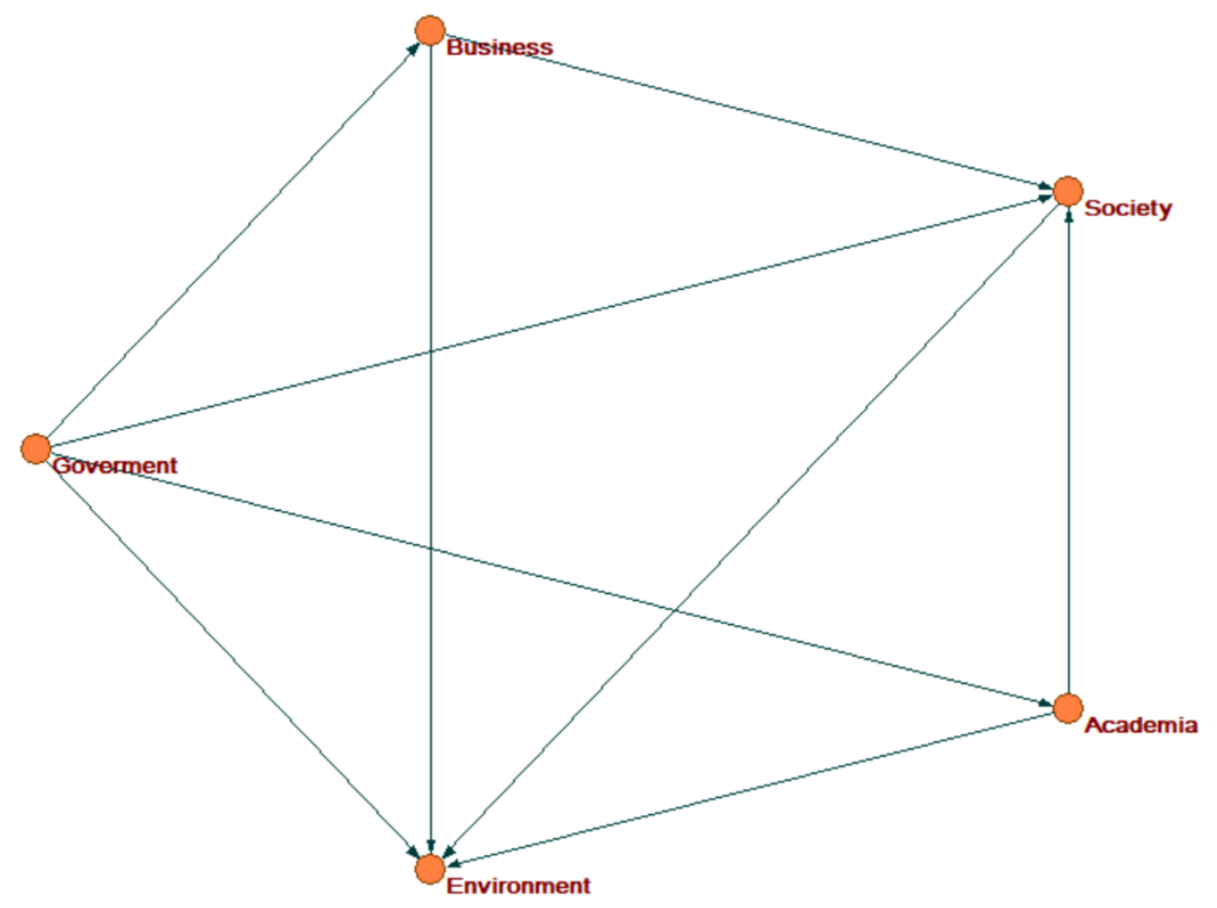

Figure 6. Relationship between the institution sectors and the application sector of SAK's experiences.

On the other hand, links were established between the business sector, with society and the environment, the society sector with the environment, and the academic sector with society and the environment.

In particular, eight institutions made up the academy (38.10\% of the total number of institutions), most of which were universities. The government and society sector ranked second, with four 
institutions each (19.05\% and 19.05\%). In third place was the business sector, with three institutions $(14.28 \%)$ and, finally, two in the environmental sector (9.52\%) (Table 3$)$.

Table 3. Institutions that had developed experiences of SAK, classified according to the pentahelix's sector.

\begin{tabular}{|c|c|c|}
\hline Reference & Institutions & Pentahelix's Sector \\
\hline 39 & National Institute of Public Health (INSP) & \multirow{5}{*}{ Government } \\
\hline 40 & Government of the Department of Atlántico and Colciencias & \\
\hline 41 & National Institute of Agricultural Research (INIA) & \\
\hline 42 & Consejo Veracruzano de Investigación Científica y Desarrollo & \\
\hline 42 & Tecnológico (COVECYT) & \\
\hline 40 & ACOPI (Colombian Association of Small Industries) & \multirow{4}{*}{ Society } \\
\hline 43 & Foundations of Barranquilla & \\
\hline & +aCtitud de Clemencia & \\
\hline 44 & Risas del Sol Tours de María la Baja & \\
\hline 45 & National Experimental University of Táchira (UNET) & \multirow{8}{*}{ Academia } \\
\hline 40 & University of the Atlantic (UDA) & \\
\hline 46 & Simon Bolivar University (USB) & \\
\hline 47 & University of the Coast (CUC) & \\
\hline & El Norte University (UN) & \\
\hline & University of Antioquia Library System & \\
\hline 48 & Los Libertadores University Foundation & \\
\hline & Minuto de Dios University (UNIMINUTO) & \\
\hline 40 & Electricaribe & \multirow{3}{*}{ Business } \\
\hline 49 & National Federation of Colombian Coffee Growers & \\
\hline 50 & Maloka Corporation & \\
\hline 51 & Chamela Biological Research Station & \multirow{2}{*}{ Environment } \\
\hline 52 & Bogota Botanical Garden & \\
\hline
\end{tabular}

\subsection{RQ5. What Was the Purpose of the Experiences of Social Appropriation of Knowledge}

The purpose of each SAK experience was different, each one focused on the local improvement area where the experience was developed. These were:

- Establish a knowledge network on sexual and reproductive health [39].

- Development of workshops, talks, sociograms on renewable and sustainable alternative energies [40].

- Development of green manure technology [41].

- To bring scientific and technological knowledge closer to the population [42].

- $\quad$ Recovery of public spaces in Barranquilla [43].

- To promote the management of ICT, culture, and identity of the municipalities [44].

- Execution of a program to rescue "Cacao criollo" [45].

- Elaboration of the thesaurus of the Colombian Literature Information System [46].

- Design, implement, and validate a de-infoxing model [47].

- Apply transference and SAK to determine human ecology in the context of the city of Bogotá [48].

- Generate content for a series of communication and information strategies to disseminate and connect their rural consumers through tablets [49].

- Building an interactive experience on nanotechnology [50].

- Strengthen processes of linkage between scientists and the rural population, in order to improve the transition to sustainable socio-ecological systems [51].

- Provide clear practical information in colloquial language on the sustainable use of plant resources [52]. 


\section{Discussion}

The data obtained from the literature review showed the current picture of SAK's experiences. Likewise, the 14 localized experiences responded to the indicators of SAK identification established by Daza-Caceido et al. [21]. In particular, all experiences focused on the interest in science and technology and the social development of the environment, as stated in the response to RQ5. This denoted the alignment of the practical experiences with the theoretical principles of the SAK.

On the other hand, the small number of publications in the 2009-2019 period and the increase in articles on SAK experiences in the last five years indicated that the SAK is an emerging term that will set the political agenda for the coming years. Thus, one of the main findings is located in the fact that all experiences of SAK were developed in Latin America, especially in Colombia. This might be a direct cause of the Colombian government's national strategy for SAK [14], which it has been developing since 2010. Furthermore, interest in SAK was highlighted as one of the concerns of Latin American countries $[15,16]$. This was reflected in the location of the SAK experiences, which were developed in Mexico, Colombia, Venezuela, and Uruguay, as shown in Figure 4. Therefore, Latin America is at the forefront of SAK's actions. This might be due to the social condition of Latin American countries, which require initiatives that help local development in a sustainable way, unlike Europe, where the socio-economic level of its inhabitants is not so unequal and local development initiatives are less numerous. This trend is reversed with initiatives such as the digital manufacturing laboratories (Fab Lab) and the open innovation laboratories that are being set up in many European cities. However, their impact is minimal compared to Latin America.

With respect to the sectors of the pentahelix where the SAK experiences were developed, the concreteness of the themes and their typology responded to four of the five sectors [26]. Likewise, the government sector was not subject to the development of SAK experiences. Government-owned institutions developed SAK experiences in all other sectors, as shown in Figure 6. However, most experiences focused on the social sector, so the primary interest was social improvement. The environment was also of interest, being the second sector with the greatest number of experiences. However, it should be mentioned that the academy and the business were also objects of interest. These data showed that the government sector implemented SAK strategies in other sectors that made up the pentahelix.

For their part, the majority of the weight in the development of SAK experiences was carried by academia (mainly universities), with these actions forming a part of social innovation and regional development programs [25]. Academia has focused on the sector of society, above all, implying the establishment of a close link between these two sectors Thus, the main objective of the academy was to improve the social environment $[18,19]$. This link highlights the University's aim to return to society some of the knowledge that is generated in academia. This is key for SAK, since knowledge is mainly generated in universities through the work of researchers. The academic sector must therefore be the main driving force behind SAK strategies.

The purposes established in each SAK's experiences were diverse, in pursuit of social and institutional improvement, and some even aimed at improving the business fabric. Therefore, the SAK served as a strategy to stimulate economic development [17], through social innovation [18-20]. In consideration, a reciprocal relationship was established between the SAK and social innovation, where the SAK acted as a motor for social innovation and this, in turn, was a fundamental part of the SAK, as reflected in RQ5. This relationship was reflected in the objectives and experiences carried out in the articles, which showed how social innovation and SAK were closely linked. On the other hand, other SAK experiences, gathered in this study, resulted in the creation of scientific archives that made information open and accessible to the public [20]. This diversity of objectives showed that the experiences of SAK developed so far encompassed different key aspects for regional and social development. Furthermore, the actions of SAKs highlight the importance of generating knowledge that has an impact on society, as the data collected showed that there were many experiences that could be carried out through the application of scientific knowledge. 
Finally, the experiences of SAK were linked to the SDGs of — good health and well-being; quality education; gender equality; affordable and clean energy; decent work and economic growth; industry, innovation, and infrastructure; reduced inequalities; sustainable cities and communities; responsible consumption and production; climate action; life on land; and peace, justice and strong institutions [28]. This relationship with the SDG could be seen in the general objectives of the SAK experiences in RQ5. The main implication of the fact that SAK's experiences were related to SDG, denotes the adequacy of this strategy at present and in the coming years, in line with international treaties on sustainable development. Based on this, that the experiences of SAK are linked to the SDG is an important indicator in establishing future strategies, since the SAK is aligned within a global framework of sustainable actions.

\section{Conclusions}

The possibility of bringing scientific knowledge closer to the population is a powerful tool for empowering citizens and providing them with tools and resources that contribute to the improvement of their immediate environment. Therefore, the SAK is key in the 21st century, in order to progress as a society. This is a feasible fact that some governments are aware of and have established strategies to encourage experiences along these lines. Thus, it does not mean that the SAK emerges as an alternative to failure in schools, but rather that it is in line with taking advantage of the knowledge of universities that is often lost or is only used by academics.

Specifically, this literature review article focused on identifying the context and purpose of the SAK experiences, while also looking at the linkage to pentahelix sectors. On this basis, different research questions were answered that served to establish the data-number of studies, geographical distribution, pentahelix sector, institutions, and objectives.

Among the limitations of the study, the reduced size of the analyzed sample should be highlighted. However, this was a faithful reflection of the development of the subject over the last 10 years, as indexed in the main scientific databases. In this sense, the fact that only two databases were used was another limitation. However, for a first approach it was convenient to review the literature that is indexed by quality and impact criteria.

Future lines of research could continue investigating the experiences of SAK, since this is a descriptor that will mark a large part of the actions of the future. This is already happening, as the experiences in this paper show. Furthermore, the trend that governments are betting on is to use their own potential to favor local and regional development. This could be extracted from the knowledge generated in universities through knowledge transfer plans. Also of interest is the analysis of the motivations or funding behind the SAK experiences developed by the institutions. This could help detect the support and interests behind supporting certain SAK actions.

Finally, the SAK involves certain mechanisms of social entropy that drive social development and innovation. At the same time, it is closely linked to the SDG of UN's Agenda 2030.

Author Contributions: Conceptualization, J.-M.R.-R. and I.A.-D.; methodology, M.-S.R.-M. and F.-J.H.-L.; software, I.A.-D.; formal analysis, M.-S.R.-M.; investigation, I.A.-D., M.-S.R.-M., F.-J.H.-L. and J.-M.R.-R.; writing-original draft preparation, I.A.-D., M.-S.R.-M. and J.-M.R.-R.; writing-review and editing, I.A.-D., M.-S.R.-M., F.-J.H.-L. and J.-M.R.-R.; visualization, F.-J.H.-L.; supervision, J.-M.R.-R. All authors have read and agreed to the published version of the manuscript.

Funding: State Programme for the Promotion of Talent and its Employability; State Sub-Programme for the Mobility of Short Stays; and Temporary Transfers of the Ministry of Science, Innovation and Universities of the Spanish Government (Project reference: EST18/00046).

Acknowledgments: We would like to convey our acknowledgements to the researchers of the research group AREA (HUM-672) of the University of Granada, and the researchers of School of Humanities and Education, Tecnológico de Monterrey.

Conflicts of Interest: The authors declare no conflict of interest. 


\section{References}

1. Álvarez, L.; de La Fuente, H. The Social Appropriation of Science as Counter-Hegemony: Technology Challenges Facing Bolivia and Venezuela. Perspect. Global Dev. Technol. 2012, 11, 401-413.

2. Holmes, S.; Smart, P. Exploring open innovation practice in firm-nonprofit engagements: A corporate social responsibility perspective. RD Manag. 2009, 39, 394-409. [CrossRef]

3. Yun, J.J.; Park, K.B.; Im, C.; Shin, C.; Zhao, X. Dynamics of Social Enterprises-Shift from Social Innovation to Open Innovation. Sci. Technol. Soc. 2017, 22, 425-439. [CrossRef]

4. Pardo, C.I.; Cotte, A. Knowledge and Perceptions of Open Science among Researchers-A Case Study for Colombia. Information 2018, 9, 92.

5. Marín, J.A.; López, J.; Fernández, J.M.; Romero, J.M. Big Data in Education: A Bibliometric Review. Soc. Sci. 2019, 8, 223. [CrossRef]

6. Stamm, T. From honest mistakes to fake news-Approaches to correcting the scientific literature. Head Face Med. 2020, 16, 6. [CrossRef]

7. Yun, J.J.; Egbetoku, A.A.; Zhao, X. How Does a Social Open Innovation Succeed? Learning from Burro Battery and Grassroots Innovation Festival of India. Sci. Technol. Soc. 2019, 24, 122-143. [CrossRef]

8. Dahlander, L.; Gann, D.M. How open is innovation? Res. Policy 2010, 39, 699-709. [CrossRef]

9. Bogers, M.; Chesbrough, H.; Moedas, C. Open Innovation: Research, Practices, and Policies. Calif. Manag. Rev. 2018, 60, 5-16. [CrossRef]

10. Barbón, O.G.; Añorga, J. Conceptual coordinates that contribute to the understanding of Advanced Education as an educational social movement. Revista cubana de Reumatología 2015, 17, 140-146.

11. Berg, L.N. System of legal impact from social entropy to legal development. Quid-Investigación Ciencia y Tecnología 2018, 2, 133-137.

12. Matei, S.A.; Bruno, R.J. Pareto's 80/20 law and social differentiation: A social entropy perspective. Public Relat. Rev. 2015, 41, 178-186. [CrossRef]

13. Rodríguez, R.A.; Riera, R.; Reyes, I.; Delgado, J.D. Entropy vs. human ontogeny: The Shannon information measure; a reliable general indicator of human health? Interdiscip. Sci. Rev. 2019, in press.

14. Departamento Administrativo de Ciencia, Tecnología e Innovación -Colciencias-. Estrategia Nacional de Apropiación de la Ciencia, la Tecnología y la Innovación; Colciencias: Bogotá, Colombia, 2010.

15. Massarani, L.; Moreira, I.C. Science communication in Brazil: A historical review and considerations about the current situation. Anais da Academia Brasileira de Ciências 2016, 88, 1577-1595. [CrossRef]

16. Melo, D.F.; Silva, J.A.; Indacochea, L.R.; Núñez, J.H. Technologies in Higher Education: Public Policies and Social Appropriation of their Implementation. Rev. Digit. Invest. Docencia Univ. 2017, 11, 193-206.

17. Quintero, D.; Zamora, N. An approach to the concept of social appropriation of knowledge: From the traditional knowledge of Afro-Colombian and indigenous communities. Uni-pluri/versidad 2017, 17, 50-58.

18. Uribe-Tirado, A.; Ochoa-Gutiérrez, J.; Medina-Alfonso, D. Visibility of the University of Antioquia Researchers in International, National and Regional-Local Media. Revista Interamericana de Bibliotecología 2019, 42, 107-126.

19. Vaccarezza, L. Social appropriation and hybridization of knowledge in university extension processes. Cuestiones de Sociología 2015, 12, 1-17.

20. Marín, S.A. Social appropriation of knowledge: A new dimension of archives. Revista Interamericana de Bibliotecología 2012, 35, 55-62.

21. Daza-Caceido, S.; Maldonado, O.; Arboleda-Castrillón, T.; Falla, S.; Moreno, P.; Tafur-Sequera, M.; Papagayo, D. Measuring the impact of practices of social appropriation of science and technology: A proposal for a set of indicators. História, Ciências, Saúde—Manguinhos 2017, 24, 145-164.

22. Departamento Administrativo de Ciencia, Tecnología e Innovación-Colciencias-. Deslocalizando la apropiación social de la ciencia y la tecnología en Colombia. Aportes desde prácticas diversas; Colciencias: Bogotá, Colombia, 2010.

23. Pérez, M.C.; Vladimirovna, N. Scientific production on social innovation for local development. A bibliometric review. Prism. Soc. 2017, 19, 147-182.

24. Martínez-Celorrio, X. Social innovation: Origins, trends and ambivalence. Sistema 2017, 247, 61-88.

25. Melamed-Varela, E.; Navarro-Vargas, L.; Blanco-Ariza, A.B.; Olivero-Vega, E. University-IndustryGovernment linkage to promote innovation at regional systems: Documentary research. Revista de Estudios Regionales 2019, 114, 147-169. 
26. Consejo Nacional de Ciencia y Tecnología-CONACyT-. Programa Estratégico Nacional de Tecnología e Innovación Abierta (PENTA); Conacyt: México City, Mexico, 2019.

27. Yun, J.J.; Liu, Z. Micro- and Macro-Dynamics of Open Innovation with a Quadruple-Helix Model. Sustainability 2019, 11, 3301. [CrossRef]

28. United Nations (UN). Transforming our world: The 2030 Agenda for Sustainable Development; United Nations: New York, NY, USA, 2015.

29. Manterola, C.; Astudillo, P.; Arias, E.; Claros, C. Systematic reviews of the literature: What should be known about them? Cirugía Española 2013, 91, 149-155. [CrossRef] [PubMed]

30. Ramírez-Montoya, M.S.; García-Peñalvo, F.J. Co-creation and open innovation: Systematic literature review. Comunicar 2018, 26, 9-18. [CrossRef]

31. Kroll, J.; Richardson, I.; Prikladnicki, R.; Audy, J.L.N. Empirical Evidence in Follow the Sun Software Development: A Systematic Mapping Study. Inf. Softw. Technol. 2018, 93, 30-44. [CrossRef]

32. Moher, D.; Liberati, A.; Tetzla, J.; Altman, D.G. PRISMA Group Preferred Reporting Items for Systematic Reviews and Meta-Analyses: The PRISMA Statement. PLoS Med. 2009, 6, e1000097. [CrossRef]

33. Alonso-García, S.; Aznar-Díaz, I.; Cáceres-Reche, M.P.; Trujillo-Torres, J.M.; Romero-Rodríguez, J.M. Systematic Review of Good Teaching Practices with ICT in Spanish Higher Education. Trends and Challenges for Sustainability. Sustainability 2019, 11, 7150. [CrossRef]

34. García-González, A.; Ramírez-Montoya, M.S. Systematic Mapping of Scientific Production on Open Innovation (2015-2018): Opportunities for Sustainable Training Environments. Sustainability 2019, 11, 1791. [CrossRef]

35. Kitchenham, B.; Pretorius, R.; Budgen, D.; Brereton, O.P.; Turner, M.; Niazi, M.; Linkman, S. Systematic literature reviews in software engineering-a tertiary study. Inf. Softw. Technol. 2010, 52, 792-805. [CrossRef]

36. Moreno, A.; Gómez-García, G.; López-Belmonte, J.; Rodríguez-Jiménez, C. Internet Addiction in the Web of Science Database: A Review of the Literature with Scientific Mapping. IJERPH 2020, 17, 2753. [CrossRef] [PubMed]

37. Petersen, K.; Feldt, R.; Mujtaba, S.; Mattsson, M. Systematic Mapping Studies in Software Engineering. EASE 2008, 8, 68-77.

38. Hinojo-Lucena, F.J.; Aznar-Díaz, I.; Cáceres-Reche, M.P.; Trujillo-Torres, J.M.; Romero-Rodríguez, J.M. Problematic Internet Use as a Predictor of Eating Disorders in Students: A Systematic Review and Meta-Analysis Study. Nutrients 2019, 11, 2151. [CrossRef]

39. Cash-Gibson, L.; Guerra, G.; Salgado-de-Snyder, V.N. SDH-NET: A South-North-South collaboration to build sustainable research capacities on social determinants of health in low- and middle-income countries. Health Res. Policy Syst. 2015, 13, 45. [CrossRef] [PubMed]

40. Fábregas, C.J.; Ariza, Y.A.; Carmona, C. An approach to the theoretical explanation of sustainable development: Corporate Social Responsibility. Espacios 2018, 39, 20.

41. Albicette-Bastreri, M.M.; Chiappe-Hernández, M. An experience of participatory research in Uruguay. Agric. Sociedad y Desarrollo 2012, 9, 30-54.

42. Valdez, L.; Aguilar-Duarte, A.E.; Contreras, H.G. The mobile museum El Camino de la Ciencia (The Way of Science) as a developer of outreach science and social appropriation of scientific knowledge. Revista Eureka sobre Enseñanza y Divulgación de las Ciencias 2014, 11, 13-21.

43. Santamaría-Ramos, J.; Madariaga-Orozco, C.A. Determinants of social innovation in fourth-generation foundations in Barranquilla, Colombia. Innovar 2019, 29, 113-132. [CrossRef]

44. Ortega, A.J.; Marín, K. Social innovation as a tool for social transformation of rural communities. Revista Virtual Universidad Católica del Norte 2019, 57, 87-99.

45. Díaz, Z.; González, Y. The process of social appropriation of knowledge in cocoa cooperatives in Táchira State, Venezuela. Agroalimentaria 2017, 23, 123-140.

46. Vallejo, O.; Montoya, C.A. Description of the Colombian Literature Information System thesaurus. Revista Interamericana de Bibliotecología 2009, 32, 123-146.

47. Baquero, L.; Gil, C.; Hernández, M. De-infoxing model for the teaching-learning process. Revista Redes de Ingeniería 2017, 8, 101-109.

48. Medina, I.D. Human ecology in the context of the city of Bogotá. A brief study case of application of transfer and social appropriation of knowledge: Agent-based models. Uni-pluri/versidad 2016, 16, 13-26. 
49. Zapata, M.I.; Marín, B.E. Rurality and mobile devices: Social appropriation and use of the ICT Coffee Production Tablet. Study case of Federación Nacional de Cafeteros para Antioquia. Revista Lasallista de Investigación 2015, 12, 19-27. [CrossRef]

50. Casas-Muñoz, A.; Cárdenas, L. Nano-themes... Giga-experiences. Momento 2013, 46, 105-114.

51. Castillo, A.; Vega-Rivera, J.H.; Pérez-Escobedo, M.; Romo-Díaz, G.; López-Carapia, G.; Ayala-Orozco, B. Linking social-ecological knowledge with rural communities in Mexico: Lessons and challenges toward sustainability. Ecosphere 2018, 9, e02470. [CrossRef]

52. Lozano-Borda, M.; Pérez-Bustos, T.; Roatta-Acevedo, C. Deconstructing the deficit model of social appropriation of science and technology in Colombia: The case of the handbook "Las Maticas de mi Huerta". Educar em Revista 2012, 44, 93-109. [CrossRef]

(C) 2020 by the authors. Licensee MDPI, Basel, Switzerland. This article is an open access article distributed under the terms and conditions of the Creative Commons Attribution (CC BY) license (http://creativecommons.org/licenses/by/4.0/). 